
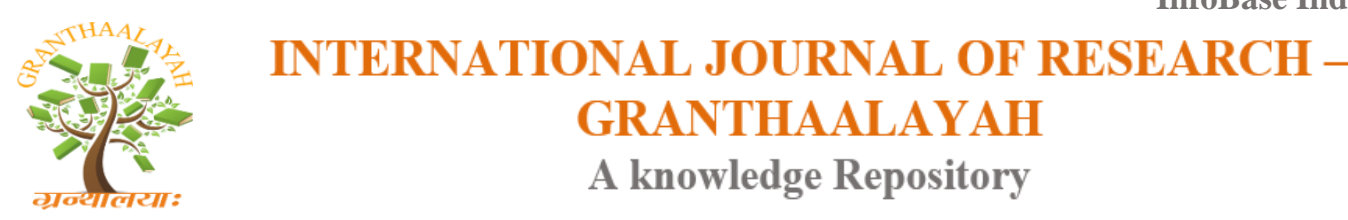

Science

\title{
PHYSICAL CIVIC ISSUES TRACKING UTILITY
}

\author{
G.K.A. Dias ${ }^{* 1}$, G. W. Wakista ${ }^{2}$ \\ ${ }^{* 1,2}$ University of Colombo School of Computing, Sri Lanka
}

DOI: https://doi.org/10.29121/granthaalayah.v5.i1.2017.1697

\begin{abstract}
Sri Lanka's economy is in a critical juncture and it is now in a stage transition to middle income economy. Still there are so many infrastructure facilities that have to be developed not only in villages but also in cities.

Due to the lack of infrastructure facilities there are so many physical civic issues still prevail in the society. Most importantly people don't have a proper mechanism to report these physical civic issues to the relevant authorities to get those issues fixed as the mechanism which is prevailing is outdated. Therefore there should be a proper mechanism to report the civic issues in a city or a village and monitor the solution process after directing the issue to the relevant authority. It makes the lives of the citizens much comfortable and happier. This proposed system will be a novel solution for the outdated reporting methods. A survey was done to gather the requirements for the system. This proposed solution will encourage the citizens to perform their civic duty in a more responsible manner. When the system is implemented the members of the local government can't wait as unseen. They have to take actions for the reported issues as the entire country is in touch about the issues.
\end{abstract}

Keywords: Civic Issues; Geo-Tagging; Physical Civic Issues.

Cite This Article: G.K.A. Dias, and G. W. Wakista. (2017). "PHYSICAL CIVIC ISSUES TRACKING UTILITY." International Journal of Research - Granthaalayah, 5(1), 99-110. https://doi.org/10.29121/granthaalayah.v5.11.2017.1697.

\section{Introduction}

Infrastructure and human resource development considered to be the back bone of the development process. Physical structures, such as roads, electricity, irrigation, water and sanitation and telecommunication are some of the areas that come under infrastructure facilities.

These infrastructure facilities not only support the production of goods and services in an economy but they also facilitate day-to-day living of the populace. 
Physical infrastructure is only part of the arsenal the Sri Lankan economy needs to make a strong middle income transition, and sustain growth over a longer period. Physical infrastructure is essential for economic growth and for Sri Lanka's transition to middle income status. Social infrastructures should also be developed at the same time.

Still there are so many infrastructure facilities in Sri Lanka that have to be developed not only in villages but also in cities. With the growth in the population there is a massive competition for the basic needs as well as for the other requirements. Social system is also becoming more complex and most of the people are spending a busy daily routine in order to earn money. Therefore infrastructure facilities play a major role in each and every citizen's life.

Due to the lack of infrastructure facilities there are so many civic issues still prevail in the society. Those civic issues can be categorized as physical civic issues, social civic issues, personal issues, etc. Physical civic issues can be categorized further based on the issues related to roads, transportation, electricity, water and sanitation, irrigation, education, telecommunication, etc. Most importantly people don't have a proper mechanism to report these physical civic issues to the relevant authorities to get those issues fixed as the mechanism which is prevailing is outdated.

Therefore there should be a proper mechanism to report the civic issues in a city or a village and monitor the solution process after directing the issue to the relevant authority. It makes the lives of the citizens much comfortable and happier.

Figure 1 shows some physical civic issues prevailing in the country.
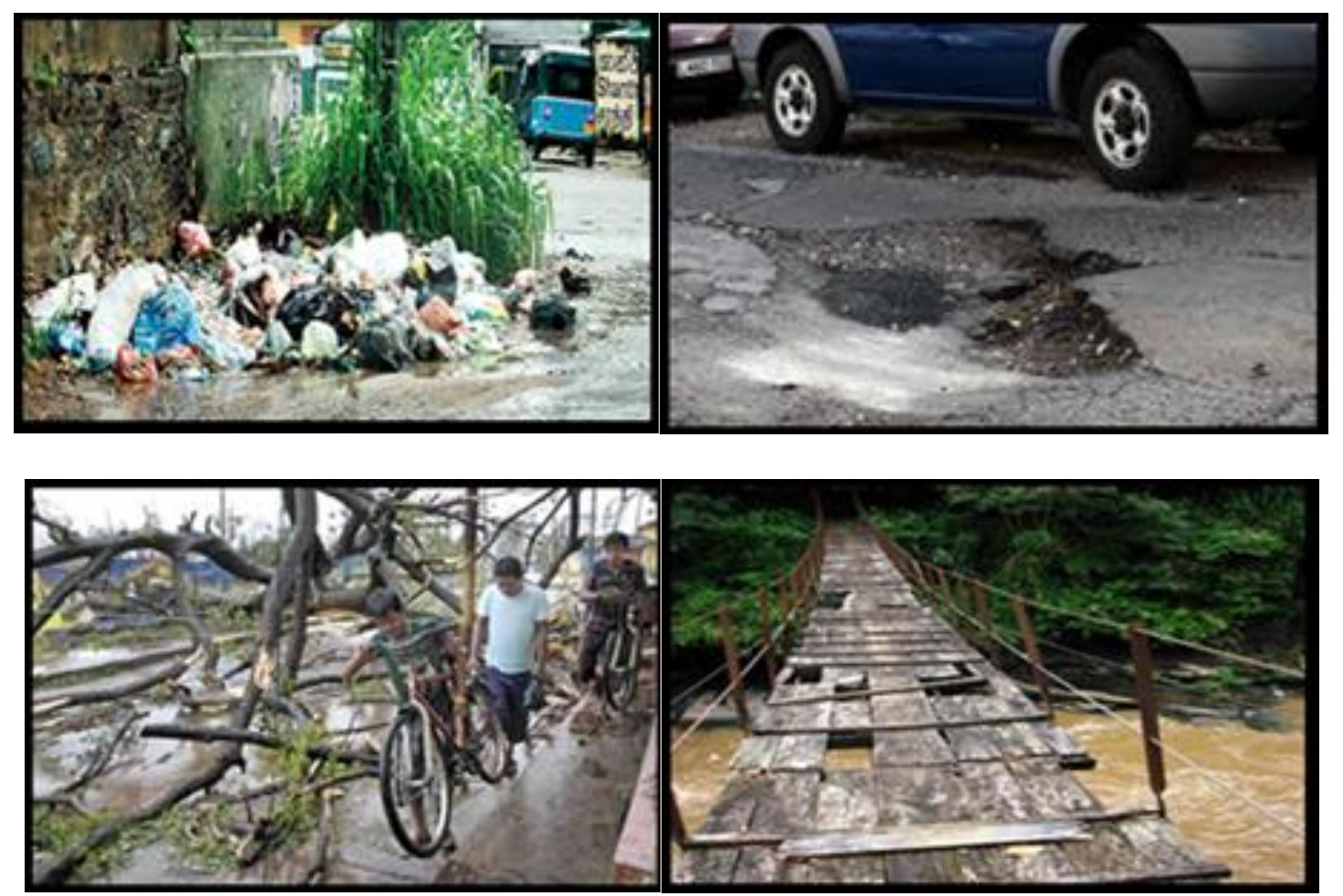

Figure 1: Physical Civic Issues 


\section{Background}

Sri Lanka has a rich and long history of local governments. Sinhalese kings used villages as a unit of administration. Each village was independently administered. Village Councils ('GamSabhas') administered local affairs, addressed people's grievances and settled minor disputes. There were 'Arachchis', 'Gammuladaneeies' (Village head) to investigate these problems and give solutions. The village based administration continued for centuries in one form or the other.

But as the population increased the local government concept and Village officer ('Grama Niladharee') concept came to the villages. Local government is the authority to provide public services to the citizens. Local government is the third and lowest level of government in Sri Lanka - after the central government and provincial councils. The local government bodies are collectively known as local authorities [1]. Local authorities are divided into three different groups; municipal councils, urban councils and divisional councils ('Pradeshiyasabha'). As of January 2011 there were 335 local authorities (23 municipal councils, 41 urban councils and 271 divisional councils) [1]. They are responsible for providing a variety of local public services including roads, sanitation, drains, housing, libraries, public parks and recreational facilities.

Local Governments are commonly accepted level of domestic governance which has been actively engaged in local development activities in our country. It provides basic service and development to citizens in the areas under its jurisdiction. Local Authorities should provide health and environmental sanitation facilities, through fares and public utility services including the provision of civic amenities with the objective of "promoting the welfare and comfort of the citizens." However, the level of local development and service delivery is far below public expectations due to a wide range of factors, some of which could be easily resolved if proper procedures were followed and accepted standards adopted [5].

Increasing urbanization will require investments in mass transit, expanded water and sewage networks, improved road safety, better control of air pollution, noise pollution, and other environmental hazards and better town planning to allow for elderly-friendly design aspects.

In 2008, the government engaged in the implementation of mega infrastructure development projects highlighted in the Randora, at the national level and the 'Gama Neguma' and 'Maga Neguma' programs at the regional level. [6]

\section{Literature Survey}

Literature surveys done on similar systems are described below.

\subsection{FixMyStreet ${ }^{[13]}$}

FixMyStreet is a website through which users can report potholes, broken street lights and similar problems with streets and roads in the United Kingdom to their local council or related organization, and see what reports have already been made. A FixMyStreet app was developed to 
enable iPhone users to report problems using their phones and since then volunteers have written apps for Nokia and Android, as well as another app for the iPhone. FixMyStreet has inspired similar sites in other countries such as Australia, Belgium, Canada, etc. User has to enter the nearby UK postcode, or street name and area. Then user has to locate the problem on a map of the area. Subsequently user has to enter the details of the issue and system will send the issue to the relevant council.

\subsection{SeeClickFix ${ }^{[12]}$}

SeeClickFix is a web tool that allows citizens to report non-emergency neighborhood issues, which are communicated to local government, as a form of community activism. It has an associated free mobile phone application.

The tool centers on a web-based map that displays all user comments. All users may add comments, suggest resolutions, or add video and picture documentation. Anyone can elect to receive email alerts based on "Watch Areas" by geographical area and filtering reports by keyword. The site allows for anonymity of reporting as a way to encourage more people to report issues, hoping for transparency that keeps civic agencies accountable.

The tool has also been made into an iPhone App, which combines GPS tracking and the iPhone's built-in camera to allow users to report issues from their mobile phones. The site contains a widget generator that provides code for creating customized displays to embed on external sites. The text widget displays a list of reported issues within the defined area, and the map widget displays them spatially using Google Maps software.

\subsection{LBS ${ }^{[11]}$}

The LBS API which is based on MLP(Mobile Location Protocol) allows Service Provider applications to send and receive location requests using a REST based API. Request Service enables the Service Provider application to request location of a particular mobile number and Idea Pro sends the location as a response. The LBS REST Service facilitates Service Providers to send requests and receive responses to and from Idea Pro. E.g.: A third party application requesting a location of a particular MSISDN (Mobile Station International Subscriber Directory Number) through LBS API and receiving the response with the location of the requested MSISDN.

\subsection{OTRS ${ }^{[13][14]}$}

OTRS (Open-source Ticket Request System) is a free and open-source trouble ticket system software package that a company, organization, or other entity can use to assign tickets to incoming queries and track further communications about them. It is a means of managing incoming inquiries, complaints, support requests, defect reports, and other communications. It is more than a mailing list notification system for ticket requests.

Every ticket generated by the system has persistence or "history" showing what happened to the ticket within its life cycle. OTRS has the ability to merge multiple requests about the same 
incident, thus making it possible to work on an incident rather than on single requests. OTRS is a multiuser system which means that multiple agents may work simultaneously on the tickets in OTRS. OTRS is highly scalable, capable of handling thousands of tickets per day and a nearly unlimited number of simultaneously working agents. Different functionalities are implemented as reusable backend modules, making it possible to create custom modules to extend the functionality of the OTRS system.

\subsection{Geo-Tagging With Android Smartphone ${ }^{[15]}$}

Geo-tagging is the act of including geographical information about where a photo was taken in with the digital photo file. By default, the camera application on your Android Smartphone has the ability to add GPS coordinates to the image file, but there are a few settings you have to change for this feature to work correctly.

Your photos can be geo-tagged with your location as long as your phone can get your position from the GPS satellites.

\subsection{Resume Screening Software ${ }^{[16]}$}

Today's resume management tools are substantially more sophisticated than the OCR(Optical Character Recognition) versions, and have the capacity to neatly handle a wide range of textbased formats and content. They typically include a module that extracts data from resumes, to evaluate and rank qualified candidates. The resume extraction tool uses advanced algorithms to scan your resume, identify text information, and categorize it using the rules of standard resume formatting. It uses data parsing and keyword recognition logic.

\section{Domain Analysis}

In Sri Lanka there are so many physical civic issues still prevailing in the villages and cities. Sometimes those issues are unattended by the local authorities or there is no one to report about those issues to the local authorities. As a result even minor issues prevail for months or years making a nuisance for the citizens. If there is a physical civic issue such as potholes, lifted manholes, uncollected trash in a village or a town, it takes time to inform to the local government. Sometimes local authorities don't know about the civics problems of the villages because no proper reporting system is available.

On the other hand individuals basically wait for the other people to take the initiative and report to the relevant authority. Most of the people don't like to take the initiative. There is no mechanism to encourage the citizens to report about the civic issues in their areas. There is also no proper way for the people in the country to make aware about the problems in a particular village unless the media visits those villages and report it.

Figure 2 summarized the physical issues identified by the respondents of the online survey. 


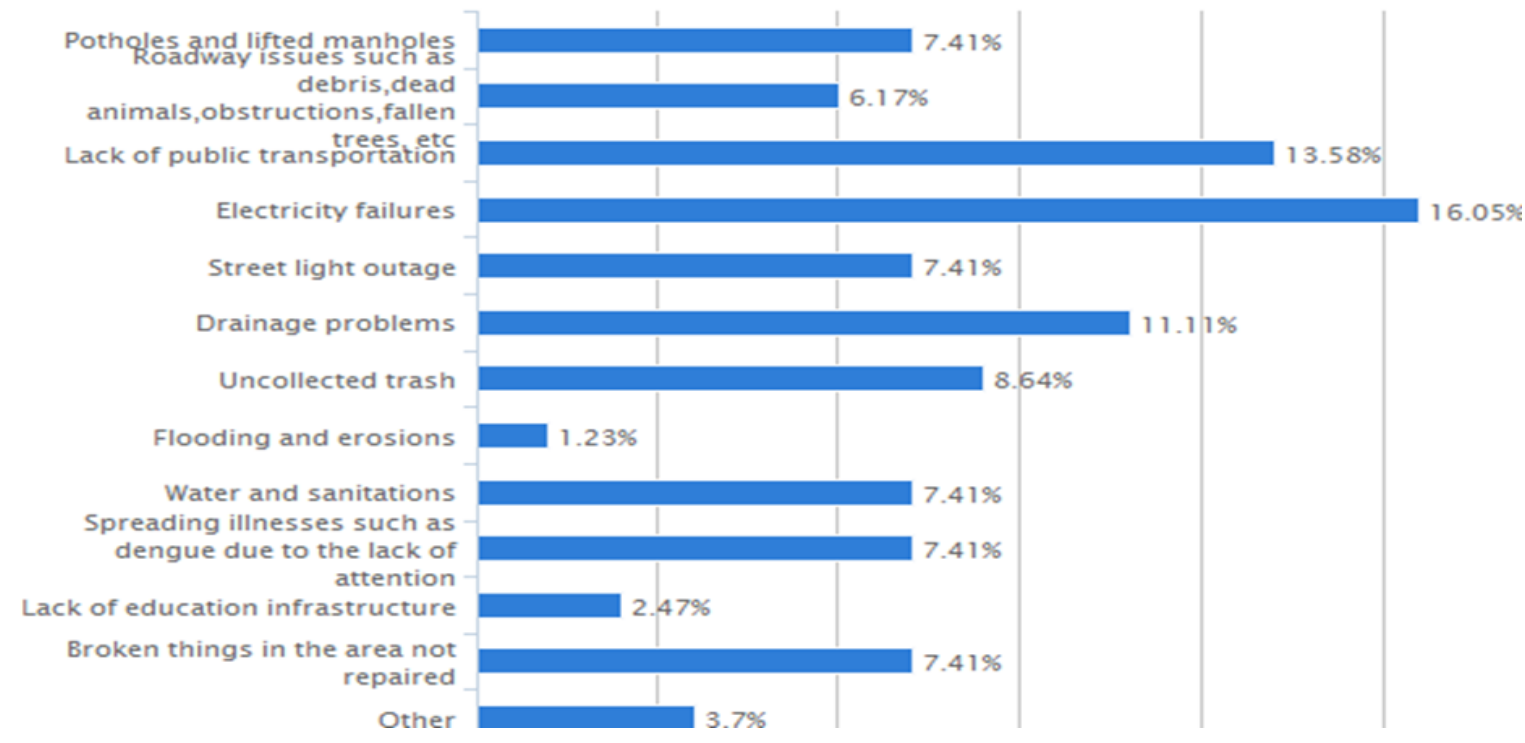

Figure 2: Physical issues identified from the survey

Figure 3 summarizes the ways that people report a physical civic issue to the local government.

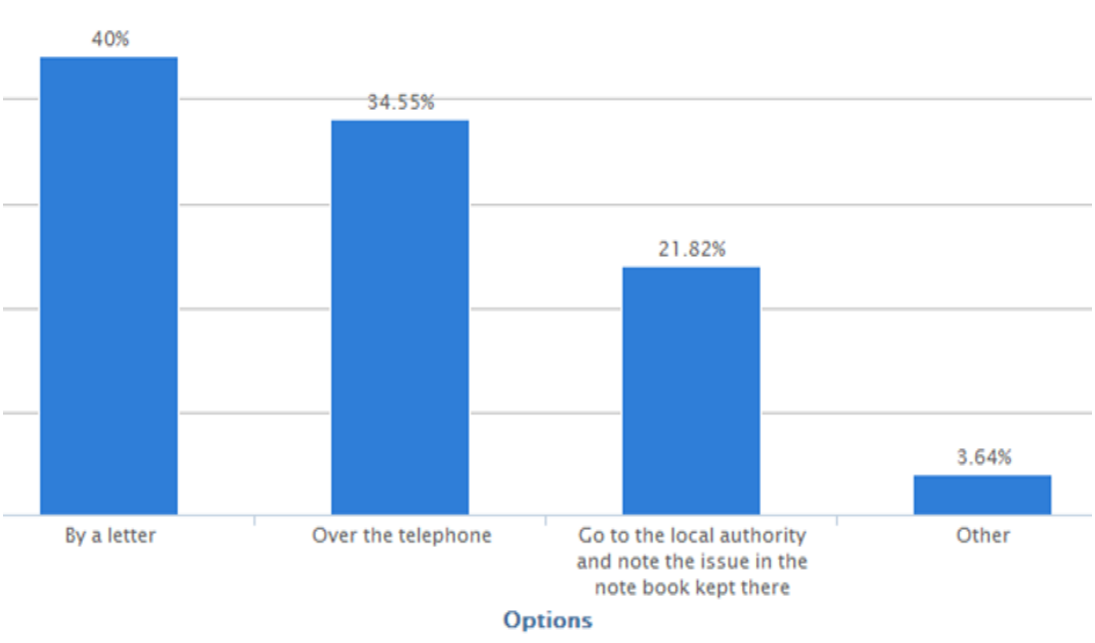

Figure 3: Different ways that people report a physical civic issue

Table 1 shows why people reluctant to report physical civic issues in their areas to relevant authorities

Table 1: Why People reluctant to report physical civic issues in their areas to relevant authorities?

\begin{tabular}{|l|l|}
\hline Reasons & $\%$ \\
\hline 1 People think others will report & $23.76 \%$ \\
\hline 2 People don't like to take the initiative & $13.86 \%$ \\
\hline 3 People don't know how to report & $13.86 \%$ \\
\hline
\end{tabular}




\begin{tabular}{|l|l|}
\hline 4 People don't pay much attention to public issues unless it affects him/her & $21.78 \%$ \\
\hline 5 Ways of reporting are outdated & $10.89 \%$ \\
\hline 6 People don't have faith in local governments & $13.86 \%$ \\
\hline 7 Other & $1.98 \%$ \\
\hline
\end{tabular}

The following question was also asked during the survey .

$\mathrm{Q}$ - If there is a system to report physical civic issues in your area, what are the characteristics that you expect from the system?

Responses are given in Table 2.

Table 2: What are the characteristics expect from the system?

\begin{tabular}{|l|l|}
\hline Characteristics & \% Responses \\
\hline 1. It should be user friendly & $23.28 \%$ \\
\hline 2. It should be less time consuming & 22.4 \\
\hline 3. User should eligible to track the status of the reported issue & $18.97 \%$ \\
\hline 4 Giving solutions to the reported issues shouldn't consume much time & $17.24 \%$ \\
\hline $\begin{array}{l}\text { 5 System should encourage the public to report the issues in their living } \\
\text { areas }\end{array}$ & $17.24 \%$ \\
\hline 6 Other & $0.86 \%$ \\
\hline
\end{tabular}

\section{Significance of the Project}

As there is no proper mechanism to report the physical civic issues to the local authorities there are so many issues prevail for so long without attending. When interviewed the relevant authorities, they stated that currently citizens can report their physical civic issues:

1) By a letter

2) Over the telephone

3) Go to the local authority and note the issue in the note book kept there.

Due to various reasons these methods have become ineffective, inefficient and outdated. Therefore people tend to consider these methods as outdated methods. There is a necessity of a new way of reporting the physical civic issues to the local authorities in a more effective way.

According to the results of the online survey, in the prevailing system most users don't know exactly where to report and how to report. But by using the proposed system reporting become a straight forward and user friendly, which takes less amount of time. When the citizens report the physical civic issues to the system, it will categorize and prioritize them. Therefore users don't need to do any work after reporting the issue.

After investigating and categorizing the reported issues those issues will be routed to the relevant local authorities to get fixed. After getting fixed local authorities inform the system and system will provide a complete report to the user about the solved issue.

Sometimes even the other interested parties also might want to know the issues in their neighborhoods. Therefore system will display the issues after the basic investigation in the website. 
Citizens can track the status of the reported issue. They can measure how efficient their local government is. Citizens can comment for the reported issues too.

Therefore proposed system urges citizens to report the physical civic issues to the local authorities quickly and it urges local governments to solve the issue as quickly as they can. It will increase the sense of belonging not only of the citizens but also of the local governments. Ultimately the project will make the living areas of the citizens more pleasant.

\section{Scope and Objectives of the Project}

\subsection{Scope of the Project}

After implementing the project citizens can report the physical civic issues in their living areas using the most feasible way in order to get those issues fixed.

- Issue reporting should be facilitated with uploading a photograph of the issue with the geotag and the description.

- System should be able to categorize those issues, filter those issues and prioritize them after a user reports an issue.

- System will route the civic issues to the relevant local authorities asking them to fix soon.

- Local authorities will inform the system when the reported civic issue was solved.

- System will inform the reported person when a physical civic issue gets solved and inform the general public via the website.

\subsection{Objectives of the Project}

Main objective of this project is to propose a feasible method to report physical civic issues while identifying and analyzing the inefficiencies and drawbacks in the current processes. Other objectives are as follows

- Make the physical civic issues reporting more effective, efficient and more user friendly.

- To empower Sri Lankans to carry out their civic duty.

- Encourage the citizens to take the initiative and report when encountering a physical civic issues. This will ensure public benefits for the whole community.

- To increases a sense of belonging of the citizens to their community by making them more relevant in the context as a community.

- To make the neighbors of that area notified and to make them aware about the issues.

- To make the members and the staff of the local authorities to attend the civic issues quickly.

- To transform the neighborhood of a citizen a pleasant place to live.

\section{Methodology}

Steps can be described briefly as given below.

- Study about the physical civic issues that the citizens encounter in their villages and cities by interviewing group of people from different villages and towns. 
- Study the ways that people report their physical civic problems to local government by selecting a group of people from different villages and towns.

- Study the ways that local governments attend to the civic issues by having discussions with local government members.

- Identify and analyze the inefficiencies and drawbacks in the current processes.

- Conduct a literature survey on methods used to report physical civic problems in other countries

- Propose possible solution to increase the efficiency of reporting civic issues in the neighborhood villages.

- Propose strategies and recommendation for the selected most feasible solution to implement.

- Find the benefits and the limitations of the feasible solution.

\subsection{Functional Requirements}

Functional requirements play a major role in the system as they define the functions of the system. The functional requirements identified are given below.

- Geo-tag feature-User should be able to report the issue with a photograph with a geo-tag and a description

- Capture, categorize and prioritize all the reported issues.

- Reporting

$>$ Issues should be reported to the relevant local authorities.

$>$ When the issue is fixed the system should be informed.

$>$ Person who reported the issue should be informed when the issue is solved.

- Acknowledgement respective users

$>$ Person when an issue is reported

$>$ Local authority mentioning the time it would take to fix the issue while publishing in the website.

- Tracking the issues -All the users of the system also should be able to track the reported issues.

- Monitoring of the Issues- New issues, unattended issues, monitoring of issues, solved issues and closed issues should be categorized by the system.

\subsection{Nonfunctional Requirements}

By using the non-functional requirements we can judge the operation of the system. Therefore identifying the non- functional requirements correctly is a must when it comes to the operation of the system.

\section{- Usability}

Reporting procedure should be usable for the general public. The language used in the system must be unambiguous and according to the context. PACT (People, Activities, Context, Technologies) analysis should be done before implementing the system to make sure it is usable. The system should be easily understood and familiar to the user because the main user group of the system is general public. 


\section{- Accuracy \& Efficiency}

All the information that is displayed in the system should be accurate. When a citizen reports a civic issue there should be an efficient mechanism in the system to direct the issue to the relevant authority and get solved with in the minimum time period. It shouldn't consist of too many steps either.

\section{- Adaptability}

System should adapt to any number of issues that come to the system.

\section{- Extendibility and Flexibility}

The system should come up with ways to customizing learning materials, and supporting major disability categories. The system should support to add new features and customize existing scenarios according to the user preference.

\section{- Availability}

It should be available for the users at any time from any place. If the available time gets increased, the number of users will be highly increased.

\section{- Reliability}

Administrators should do a basic investigation of the issue and if there are evidences to prove only, that information should be displayed and direct to the local governments.

\section{- Scalability / Maintainability}

In emergency situations, the system should be adaptable to bear huge amount of data.

The system should be easy to maintain. This applies to both the software and the hardware used.

\section{- Security}

All the private data of the users and the issues should securely maintained in the databases. Furthermore it must be capable of restricting unauthorized access to data as the issues made by users has to be kept secret. In addition the data should be backed up regularly to a secure location.

\section{Discussion and Conclusion}

Sri Lanka is increasingly investing in physical infrastructure. These forms of physical infrastructure are important to drive export led growth in a post-war context.

While revenue generated by taxation is invested in physical infrastructure, it is far from sufficient. Therefore physical civic issues are still prevailing not only in towns but also in villages

Though there are physical civic issues that should be reported for the relevant local authorities, people don't like to take the initiative due to different reasons. Therefore even the small issues last for months as there is no proper mechanism to report those issues. 
This proposed system will be a novel solution for the outdated reporting methods. This solution will encourage the citizens to perform their civic duty in a more responsible manner. This system will make increase the sense of belongings of the citizens to their community.

In the other hand members of the local government can't wait as unseen when the system implemented. They have to take actions for the reported issues as the entire country is in touch about the issues. They have to work as they came from people's votes.

As the proposed system is an effective, efficient and user friendly solution more people will grab the solution to get remedies for their physical civic issues. As a result of that living area of the citizens will be a pleasant area to live with no physical issues.

\section{Acknowledgements}

Mr. R.Yasarathne, Deputy Mayor of Matara Municipal Council and Mr.Ranjith Yapa, Urban Commissioner of Matara Municipal Council

\section{References}

[1] Local government in Sri Lanka - Wikipedia, the free encyclopedia. 2017. Local government in Sri Lanka - Wikipedia, the free encyclopedia. [ONLINE] Available at: http://en.wikipedia.org/wiki/Local_government_in_Sri_Lanka. [Accessed 3 January 2017].

[2] Report non-emergency issues; receive alerts in your neighborhood - SeeClickFix. 2017. Report non-emergency issues, receive alerts in your neighborhood - SeeClickFix. [ONLINE] Available at: http://seeclickfix.com/. [Accessed 2 January 2017].

[3] FixMyStreet2013. FixMyStreet [ONLINE] Available at: http://www.fixmystreet.com/. [Accessed 3 January 2017].

[4] Daily Mail 2013, 'IPS LAUNCHES “STATE OF THE ECONOMY 2013” TODAY Sri Lanka braces for new challenges amid economic transition' 15 October, viewed 25 October 2016,

[5] Ekanayaka, E.M.N.D.K 2011, A study on local resources mobilization for revenue o urban local authorities enhancement in Sri Lanka, Research Project, University of Moratuwa.

[6] Annual Report of 2008, Central Bank of Sri Lanka.

[7] The World Bank 2017, Sri Lanka Overview. 2017, http://www.worldbank.org/en/country/srilanka/overview

[8] World Bank, 2012. Connecting to Compete 2012, Washington: The International Bank for Reconstruction and Development/The World Bank.

[9] WEF, 2010. The Global Competitiveness Report 2010-2011, Geneva: World Economic Forum.

[10] WEF, 2011. The Global Competitiveness Report 2011-2012, Geneva: World Economic Forum.

[11] Ideamart| [ONLINE] Available at: http://www.ideamart.lk/.[Accessed 14 December 2015].

[12] SeeClickFix - at:http://en.wikipedia.org/wiki/SeeClickFix. [Accessed 13 December 2015].

[13] otrs.com | OTRS Simple Service Management. 2016. Available at: http://www.otrs.com/. [Accessed 12 July 2016].

[14] OTRS - Wikipedia, the free encyclopedia. 2016. at: http://en.wikipedia.org/wiki/OTRS[Accessed 12 December 2016].

[15] Geotagging With Android Smartphones | Chron.com. 2016. Geotagging With Android Smartphones | Chron.com. [ONLINE] Available at: http://smallbusiness.chron.com/geotagging-android-smartphones-38742.html. [Accessed 10 December 2016]. 
[16] Working With McKinsey: How the McKinsey Resume / CV Screening Process Works. 2016. [Accessed 12 December 2016].

[17] KwikSurveys: Free online survey \& questionnaire tool. 2016. KwikSurveys: Free online survey \& questionnaire tool. [ONLINE] Available at:http://kwiksurveys.com. [Accessed 09 December 2016]

\footnotetext{
*Corresponding author.

E-mail address: gkad@ucsc.cmb.ac.lk
} 